\title{
The ICF: Applications of the WHO model of functioning, disability and health to brain injury rehabilitation
}

\author{
Alvaro Bilbao ${ }^{\mathrm{a}}$, Cille Kennedy ${ }^{\mathrm{b}, *}$, Somnath Chatterji ${ }^{\mathrm{c}}$, Bedirhan Üstün ${ }^{\mathrm{c}}$, \\ José Luis Vásquez Barquero ${ }^{\mathrm{d}}$ and Jeffrey T. Barth ${ }^{\mathrm{e}}$ \\ ${ }^{a}$ Neuropsicólogo, Centro Estatal de Atención al Daão Cerebral, Madrid, Spain \\ ${ }^{\mathrm{b}}$ Department of Health and Human Services, Office of the Assistant Secretary for Planning and Evaluation, \\ Disability, Aging and Long-Term Care Policy, Washington, DC, USA \\ ${ }^{\mathrm{c}}$ Classification, Assessment, Surveys and Terminology, Global Programme on Evidence for Health Policy, World \\ Health Organization, Geneva, Switzerland \\ ${ }^{\mathrm{d}}$ Unidad de Investigación en Psiquiatría Clínica y Social, Hospital Universitario Marques de Valdecilla, \\ Santander, Spain \\ e John Edward Fowler Professor, Neuropsychology Laboratory, Department of Psychiatric Medicine, University of \\ Virginia Health System, Charlottesville, VA, USA
}

\begin{abstract}
The traditional disease and diagnostic medical model is not always useful to brain injury professionals who need to describe, measure, and compare deficits associated with neurologic insult. Professionals in neurorehabilitation are in need of new systems that will assist them in identifying impairments and areas of intervention. The aim of this article is to present the International Classification of Functioning, Disability and Health (ICF), and its applications to brain injury rehabilitation. This taxonomy, developed by the WHO, allows the classification and assessment of functioning and disability in everyday activities and social involvement for individuals with medical conditions. Multi-disciplinary teams from 65 countries have collaborated in the development of the ICF to develop a tool that serves different purposes and disciplines with high trans-cultural validity. It can be of great value for professionals working in the field of brain injury who need to describe and quantify in detail neurocognitive, emotional, and sensory-motor functions as well as their impact on activities and participation in life situations. Its applications also extend to the domains of epidemiology, public health and public policy.
\end{abstract}

Keywords: ICF, brain injury rehabilitation, WHO, classification, participation, contextual factors

\footnotetext{
*Address for correspondence: Cille Kennedy, Ph.D., DHHS/ DALTCP - Room 424E, 200 Independence Avenue, SW, Washington, DC 20201, USA. Tel.: +1 202260 0370; Fax: +1 202401 7733; E-mail: cille.kennedy@hhs.gov. Any views expressed by the author in this paper do not necessarily reflect the official views of the Office of Disability, Aging and Long-Term Care Policy, Office of the Assistant Secretary for Planning and Evaluation, Department of Health and Human Services, USA.
}

\section{Introduction}

Diagnosis is an important part of the health sciences and it is, sometimes, sufficient for determining treatment and rehabilitation. However this disease and diagnostic medical model is not always optimal when dealing with acquired brain injury. Professionals working with patients with brain injuries have an extremely complex task. Measuring physical, cognitive, and emotional capabilities; describing and comparing areas and patterns of dysfunction across time and subjects; and 
identifying, quantifying and initiating intervention are all essential aspects of their work in rehabilitation, consulting, forensic or research settings.

In November 2001, the World Health Organization (WHO) published the International Classification of Functioning, Disability and Health (ICF) [5], which is a manual that classifies health-related function and dysfunction in the physical, psychological and societal arenas. The classification is comprehensive and serves multiple purposes in the health sciences. It has wide applications to the field of brain injury rehabilitation as will be discussed in this paper.

\section{Development of the ICF}

The ICF is part of the WHO family of classifications in health. The International Classification of Disease (ICD), with its multiple versions including a specialized application for neurology (ICD-9 NA) [7], was the first attempt to develop a classification system that would standardize mortality statistics and allow the study of diseases across cultures and in populations. The ICD was an ambitious project with multitude of applications for epidemiologists, public health professionals, researchers and clinicians. Successive versions of the ICD have updated their foundations incorporating findings from the latest scientific research. The ICD is currently in its tenth version (ICD-10) [6], The WHO's definition of health, as a state of biological, psychological and social well being [9], required the incorporation of new perspectives, concepts, and classifications of health in order to allow an appropriate study of bio-psycho-social functioning. With this philosophy in mind, in 1972 the WHO began work that culminated in the publication of the International Classification of Impairments, Disabilities and Handicaps (ICIDH) [8] in 1980 for trial purposes. Although widely adopted internationally $[2,3]$, the ICIDH had a number of shortcomings from the point of view of the neuropsychologist. This was principally in relation to the organization of mental and cognitive impairments that were not represented according to any recognized conceptual framework, and moreover were insufficient, overlapping and inconsistent. Other criticisms include a failure to take into account severity and fluctuations in performance, and the role of context in determining abnormality (i.e., speech may be semantically intact but inappropriate in the social context). Also there was no allowance for the consequences of treatment effects to be considered independently of the pathology itself.
In 1993, WHO initiated the revision of the ICIDH to address the problems noted across disciplines in both the content and structure, and to incorporate advances garnered from clinical experience and scientific investigations. The revised classification, retitled as the International Classification of Functioning, Disability and Health or ICF, was developed through a three-phase, intensive 65-country field trial project. Persons from all fields of health and disability (health professionals, associations of people with disabilities, and official representatives of the different departments of health and social affairs) collaborated in the development of a classification designed to serve multiple users and disciplines. Field trial studies focused on the validity of the ICF and its cross-cultural applicability. The final version is being translated into 27 languages and is already available in all six official WHO languages: Arabic, Chinese, English, Spanish, French, and Russian.

The revision process was organized in a hierarchy of networks. Participation was primarily organized through WHO Collaborating Centres, with additional emphasis on networks, such as the Hispanic or Francophone networks, in which countries sharing a common language collaborated around language and cultural issues. In addition three International Task Forces were created to focus on special topics: mental health, children, and the environment. This effort has resulted in a classification system with high transcultural validity and a wide range of applications in the different areas of medicine and other health fields, including acquired brain injury rehabilitation.

\section{Objectives of the ICF}

The ICF has been developed within the framework of the WHO's conception of health as a state of physical and psychosocial well-being. It has been designed to complement the ICD-10, and other classifications of diseases (like the DSM-IV [1]), which focus more on the etiology of diseases and disorders, but little on the consequences or associated functional states that these disorders have on the individual. The same disorder might have very different consequences in a person's functioning, depending on the stage of the disorder, physical strength of the person, availability of health care and assistive devices, and family and social support. The ICF takes into account these variables in the classification to give an accurate description of the person's level of biological, psychological, and social 


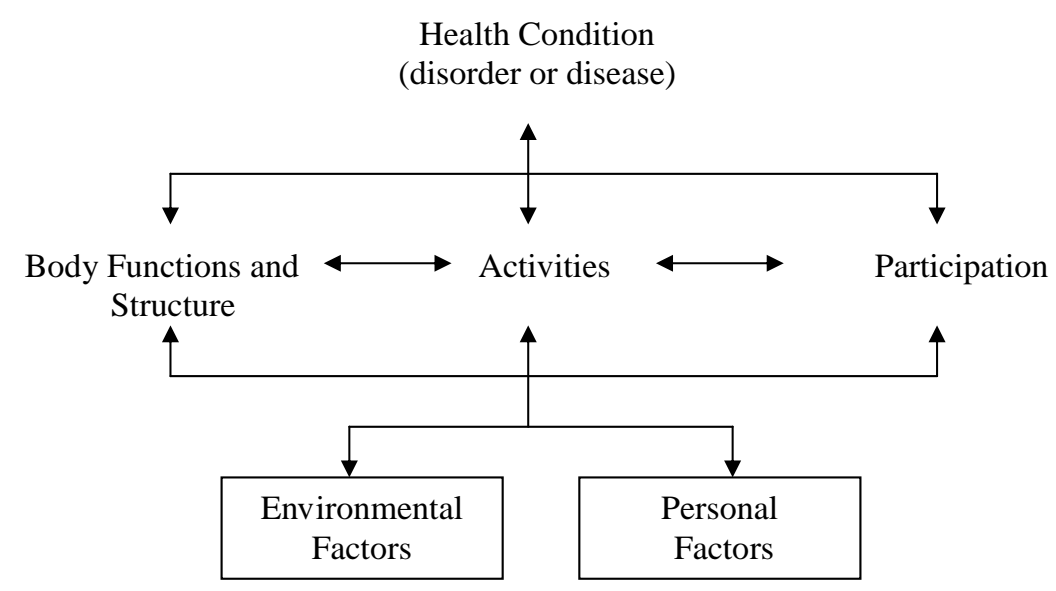

Fig. 1. Interaction between the components of ICF. (Figure 1 has been reprinted with permission of the World Health Organization (WHO), and all rights are reserved by the Organization).

functioning, and the external sources of activity limitations, indicating potential sources of intervention.

The overall aim of the ICF is to provide a unified and standardized language and framework for the description of health and health related states and their related components of well being (such as education, labor, social life, etc.). This mission has resulted in a classification that allows three main uses:

\subsection{Unified conceptual model}

The ICF classification can be used to identify and document the major factors that contribute to a specific level of functioning in health and disease. Through these analyses we will reach a better understanding of the elements and processes that occur in functioning and disability, which in turn will result in new, more effective, techniques, and strategies of intervention.

\subsection{Guide to identify sources of influence on functional states}

The classification encompasses the different areas of functioning at the individual and social levels as well as the environmental factors that interact and have an influence in the specific performance in those areas.

\subsection{Communication instrument}

Universal codification makes a better exchange of information on functioning and disability. Using a universal classification involves speaking a common language and using a consistent framework. This leads to better understanding and communication, which in turn can result in improved patient services [4].

\subsection{Other applications}

The ICF will be a tool useful for a wide variety of applications (statistical, research, clinical, social policy and educational). The ICF has been designed as a classification system, which will facilitate the collection and comparison of data on functioning and disability for epidemiological, public health research, and clinical purposes. It is an operational classification system of human functioning disability. The Classification provides a scientific basis for understanding and studying health states and health related outcomes and their determinants.

\section{The WHO model of disability}

The ICF model of functioning and disability is an interactional model, in which all elements of the system are constantly influencing and modifying the others (Fig. 1). Behavior is influenced by the environment, and by personal factors including age, gender, habits and lifestyle. But, all these factors are also influenced by each other in a continuous interactive relationship.

\subsection{Elements of the model and their relevance to brain injury rehabilitation}

The ICF model of functioning and disability includes different elements that can be divided in two main categories; levels of functioning and contextual factors.

We will review the definitions of the different components and to better illustrate the use and applications of the ICF we will apply the classification in a practical 
case. We have used the case of JM, a patient seen in a comprehensive brain injury rehabilitation center in Madrid. JM is a 33-year-old man who suffers from homocistinuria. At the time of admission JM had suffered two major strokes; one in the occipital lobe and a larger one in the right temporal-parietal area. He was admitted to participate in a six-month multidisciplinary rehabilitation program. Given the longstanding impairments and the time of evolution the program focused on reducing disability rather than trying to reduce severity of his diagnosed health condition.

\subsection{Levels of functioning}

Levels of functioning can be viewed within the context of a neutral standardized environment, or within the person's actual environment. The levels of functioning can be assessed both at the individual and societal levels. Table 1 offers a brief description of the main domains their positive and negative aspects and the application of these functions to acquired brain injury rehabilitation.

\subsection{Coding in the ICF}

Like the ICD and the DSM, ${ }^{1}$ the ICF contains alphanumeric codes. The ICD and DSM format for coding differs slightly from the ICF. The ICF uses lower case letters to designate the different sections, ' $b$ ' precedes codes for body functions, 's' precedes body structures, and 'd' precedes domains of activity and participation. The ICF uses alphanumeric codes to document the specific body level function or structure as well as particular activity that are being appraised. The first digit following the letters ' $b$ ' and 's' coincides with the body system function or structure. For example, b1 refers to Mental Functions, b2 to Sensory Functions and Pain, while s1denotes Structures of the Nervous System and s2, the Eye, Ear and Related Structures. In addition, the ICF also contains qualifiers for use with each code to document the degree of disability. Specifications about the use of qualifiers are described in Table 2.

\footnotetext{
${ }^{1}$ The DSM-IV uses $\mathrm{V}$ codes to document clinical encounters for reasons other than disease or injury. They are used to specify problems that are of sufficient severity as to warrant clinical attention, such as abuse or noncompliance with important aspects of treatment.
}

\subsection{Assessing deficits: Body structures and functions}

The Body Structures and Functions component includes the functional and structural elements of the body. The body structures are the anatomical parts of the body such as organs, limbs and their components (e.g. lobes of the brain). In the case of JM we identified three main deficits in body structures corresponding to the areas of deficit in the cortex (occipital, right parietal) and arteries (see Table 2). The body functions are the physiological aspects of the different body systems (e.g. eye-hand coordination, working memory). They include psychological functions since they are mediated by a body structure, the brain. Positive assessment of an element at this level implies structural and functional integrity. A negative evaluation of functioning at this level implies impairment at the structural or functional level. The body factor has always been included in the equation used by professionals working with patients with brain injuries to understand their patient's difficulties at different levels of functioning. JM presented mild to moderate difficulties in personality functions and most areas of higher order cognitive functions (attention, memory, executive functions). In addition moderate difficulties in perceptual functions were codified because JM presented a left side hemiagnosia, which was one of the main contributors to his limitations.

\subsection{Identifying limitations: Activities and participation}

The Activities and Participation component covers the complete range of individual and societal functioning and disability. The ICF list of activities and participation covers the range from such basic actions and tasks as learning, self care, and mobility to the more complicated actions and tasks as interpersonal interactions, work, and community life. The ICF captures the major actions that all people do regardless of culture and reflecting the lifespan.

The most important aspects of the items are the person's capacity to do them and how they actually perform them in their daily lives. For acquired brain injury rehabilitation, capacity is essentially what is assessed in the rehabilitation setting by the clinician following the traditional, approved methods. Performance is the conduct of these same actions when the patient is at home and all his other usual environments. The brain injury rehabilitation specialist may prescribe modifications to the home (or other important settings) to ac- 
Table 1

Aspects of the ICF and their contribution to neuropsychology

\begin{tabular}{|c|c|c|c|c|}
\hline \multirow[b]{2}{*}{ Components } & \multicolumn{2}{|c|}{ Part 1: Functioning and disability } & \multicolumn{2}{|c|}{ Part 2: Contextual factors } \\
\hline & $\begin{array}{l}\text { Body functions } \\
\text { and structures }\end{array}$ & $\begin{array}{l}\text { Activities and } \\
\text { participation }\end{array}$ & $\begin{array}{l}\text { Environmental } \\
\text { factors }\end{array}$ & Personal factors \\
\hline Domains & $\begin{array}{l}\text { Body functions } \\
\text { Body structures }\end{array}$ & $\begin{array}{l}\text { Life areas } \\
\text { (tasks, actions) }\end{array}$ & $\begin{array}{l}\text { External influences } \\
\text { on functioning and } \\
\text { disability }\end{array}$ & $\begin{array}{l}\text { Internal influences } \\
\text { on functioning and } \\
\text { disability }\end{array}$ \\
\hline Constructs & $\begin{array}{l}\text { Change in body } \\
\text { functions } \\
\text { (physiological) } \\
\text { Change in body } \\
\text { structure (anatomical) }\end{array}$ & $\begin{array}{l}\text { Capacity } \\
\text { Executing tasks in } \\
\text { a standard } \\
\text { environment } \\
\text { Performance } \\
\text { Executing tasks in } \\
\text { the current } \\
\text { environment } \\
\text { ning }\end{array}$ & $\begin{array}{l}\text { Facilitating or } \\
\text { hindering impact } \\
\text { of features of the } \\
\text { physical, social, } \\
\text { and attitudinal } \\
\text { world }\end{array}$ & $\begin{array}{l}\text { The impact of } \\
\text { attributes of the } \\
\text { person }\end{array}$ \\
\hline $\begin{array}{l}\text { Positive } \\
\text { Aspects }\end{array}$ & $\begin{array}{l}\text { Functional and } \\
\text { structural integrity }\end{array}$ & $\begin{array}{l}\text { Activities } \\
\text { Participation } \\
\text { ility }\end{array}$ & Facilitators & Not applicable \\
\hline $\begin{array}{l}\text { Negative } \\
\text { Aspects }\end{array}$ & Impairment & $\begin{array}{l}\text { Activity limitation } \\
\text { Participation } \\
\text { restriction }\end{array}$ & $\begin{array}{l}\text { Barriers/ } \\
\text { hindrances }\end{array}$ & Not applicable \\
\hline $\begin{array}{l}\text { Contribution } \\
\text { to brain injury } \\
\text { rehabilitation }\end{array}$ & $\begin{array}{l}\text { Detailed } \\
\text { description and } \\
\text { codification system } \\
\text { of brain structures } \\
\text { and global and } \\
\text { specific } \\
\text { psychological and } \\
\text { mental functions }\end{array}$ & $\begin{array}{l}\text { Standardized } \\
\text { measures of task } \\
\text { function. Emphasis in } \\
\text { assessment of } \\
\text { capacity and } \\
\text { performance } \\
\text { allows } \\
\text { comparisons } \\
\text { between expected } \\
\text { and actual } \\
\text { functioning }\end{array}$ & $\begin{array}{l}\text { Standardized } \\
\text { assessment of } \\
\text { environmental } \\
\text { factors which have } \\
\text { an influence in } \\
\text { functioning }\end{array}$ & $\begin{array}{l}\text { Provides age, } \\
\text { gender and other } \\
\text { person-specific } \\
\text { information as } \\
\text { context for } \\
\text { rehabilitation } \\
\text { intervention and } \\
\text { prognosis. }\end{array}$ \\
\hline
\end{tabular}

commodate the patient. In doing so, these changes to the environment will increase the person's daily performance to reflect his true capacity as it was assessed by the specialist in the clinical setting.

When assessing the Activities and Participation constructs one can focus on what the patient does in their current environment (Performance) or the highest level of functioning for an individual in a neutral environment (Capacity). Both are important factors and evaluation discrepancy between the patient's capacities and his/her actual functioning and the contributions of variables such as corporal environmental or personal world can be useful in rehabilitation efforts. These two variables are coded as qualifiers of the Activities and Participation items. Thus, limitations/restrictions at the performance level indicate a need for intervention in that person's environment. Limitations or restrictions at the Capacity level represent the discordance between the person's capacities and that of a person without the health related condition. Thus, limitations/restrictions at the capacity level indicate a need for pharmacological, physical, occupational, cognitive or speech therapy, or the implementation of compensatory strategies.

The Activities and Participation component introduces new concepts and applications in the field of brain injury rehabilitation. Brain injury professionals have typically worked at the capacity level, assessing cognitive, language, motor, and physical abilities that have implications for real life functioning. The performance level reflects what a person is doing at home, in his real life. In addition the capacity-performance dichotomy opens the possibility of a more accurate study and assessment of physical, emotional, and cognitive capabilities as they relate to true functioning. An example of a recently developed instrument that has adopted this philosophy is the Brief Rating Scale for Executive Functioning (BRIEF). This scale, developed through intensive behavioral observations, allows a standardized assessment at home or school of difficulties in executive functioning in children and adolescents. This 
Table 2

Qualifiers for each ICF component

\begin{tabular}{|c|c|c|c|}
\hline Components & First qualifier: Generic & Second qualifier & Third qualifier \\
\hline $\begin{array}{l}\text { Body function } \\
\text { (b) }\end{array}$ & $\begin{array}{l}\text { Extent of impairment - Negative scale } \\
\text { indicates the impairment's extent or } \\
\text { magnitude - Same scale as extent of } \\
\text { impairment below. }\end{array}$ & None & None \\
\hline $\begin{array}{l}\text { Body structure } \\
\text { (s) }\end{array}$ & $\begin{array}{l}\text { Extent of impairment: Negative scale } \\
\text { indicates the impairment's extent or } \\
\text { magnitude - } \\
0=\text { No problem (none, absent, } \\
\text { negligible. . .) } \\
1=\text { Mild problem (slight, low... ) } \\
2=\text { Moderate problem (medium, } \\
\text { fair. . ) } \\
\begin{array}{l}3=\text { Severe problem (high, extreme } \\
\ldots \text { ) } \\
4=\text { Complete problem (total) } \\
8=\text { Not specified } \\
9=\text { Not applicable }\end{array}\end{array}$ & $\begin{array}{l}\text { Nature of Impairment: Nominal scale } \\
\text { identifies the impairment's nature }- \\
0=\text { no change in structure } \\
1=\text { total absence } \\
2=\text { partial absence } \\
3=\text { additional part } \\
4=\text { aberrant dimensions } \\
5=\text { discontinuity } \\
6=\text { deviating position } \\
7=\text { qualitative changes in structure, in- } \\
\text { cluding accumulation of fluid } \\
8=\text { not specified } \\
9=\text { not applicable }\end{array}$ & $\begin{array}{l}\text { Location of Impairment: Nominal scale } \\
\text { identifies the impairment's location. } \\
\text { This qualifier is suggested }- \\
0=\text { more than one region } \\
1=\text { right } \\
2=\text { left } \\
3=\text { both sides } \\
4=\text { front } \\
5=\text { back } \\
6=\text { proximal } \\
7=\text { distal } \\
8=\text { not specified } \\
9=\text { not applicable }\end{array}$ \\
\hline $\begin{array}{l}\text { Activities } \\
\text { and Participa- } \\
\text { tion (d) }\end{array}$ & $\begin{array}{l}\text { Extent of Performance (i.e., limita- } \\
\text { tion in doing an activity or restriction } \\
\text { in participation): Negative scale indi- } \\
\text { cates degree of difficulty executing a } \\
\text { task in the person's current environ- } \\
\text { ment. } \\
\text { Same scale as Extent of Impairment } \\
\text { above. }\end{array}$ & $\begin{array}{l}\text { Extent of Capacity: Negative scale that } \\
\text { indicates degree of problem in ability to } \\
\text { execute a task in a standard environment. } \\
\text { Same scale as Extent of Impairment. }\end{array}$ & $\begin{array}{l}\text { Optional additional qualifiers suggested } \\
\text { in ICF. }\end{array}$ \\
\hline $\begin{array}{l}\text { Environmental } \\
\text { factors (e) }\end{array}$ & $\begin{array}{l}\text { Extent of impact: Negative and pos- } \\
\text { itive scale denotes extent of barriers } \\
\text { and facilitators respectively. } \\
\text { Same scale as extent of impairment } \\
\text { above. Add ' }+ \text { ' to scale to indicate } \\
\text { facilitator. }\end{array}$ & None & None \\
\hline
\end{tabular}

Table 2 is an adapted version of the original ICF Table 3. Qualifiers, page 24, and has been adapted and reprinted with the permission of the World Health Organization (WHO). All rights to the original table are reserved by the Organization.

is a useful instrument for clinical practice since other assessment measures that evaluate executive capabilities, such as the Wisconsin Card Sorting Test, have not always been successful in predicting and describing dysexecutive behavior in context (ecological validity). But beyond its clinical applications the BRIEF opens new and exciting areas of research and instrument development in order to better understand and predict executive problems.

Another contribution of the Activities and Participation component is the emphasis on social involvement. This is an area that has not been fully explored in brain injury rehabilitation. Therefore the development of the participation domain may add new areas of research, instrument development, and clinical assessment related to the relationships between cognitive abilities and participation in the different aspects of social functioning. The classification of social difficulties at home, work, school and the community will encourage standardized observations and thus the identification of correlates of social pitfall allowing for a more successful prediction and intervention for social difficulties associated with brain injury.

Table 4 represents main limitations in JM's performance in functioning at both individual and societal levels in his daily life before and after discharge from the rehabilitation program. Training in activities of daily living (ADLs) and the use of assistive devices were main contributors of the great improvement in independence for ADLs. Training in focusing attention, organization, planning and problem solving contributed to his improvement in many related domains such as making decisions, conversational skills or being able to listen to a radio program. Physical therapy focusing on gait disturbances and Occupational Therapy focusing on compensating for visual deficits permitted greater independence in walking inside buildings and on the street but also on reading. In addition to cognitive therapy to improve conversational organization speech therapy centered in improving non-verbal 
Table 3

Example of the ICF body structures and body functions components to describe changes in JM's impairments before and after the intervention

\begin{tabular}{|c|c|c|c|}
\hline \multirow[t]{2}{*}{ Code } & \multirow[t]{2}{*}{ Item Name } & \multicolumn{2}{|c|}{ Qualifiers } \\
\hline & & Before & After \\
\hline s110 & Brain structures & & \\
\hline s11002 & Parietal lobe (right side) & 121 & 121 \\
\hline s11003 & Occipital lobe (both sides) & 123 & 123 \\
\hline s410 & Cardiovascular system structures & & \\
\hline s4101 & Arteries (moderate alteration) & 278 & 278 \\
\hline b126 & Temperament and personality functions: & & \\
\hline b1260 & Extraversion & 2 & 2 \\
\hline b1261 & Agreeableness & 1 & 1 \\
\hline b1264 & Openness to experience & 2 & 2 \\
\hline b1265 & Optimism & 3 & 2 \\
\hline b1266 & Confidence & 2 & 1 \\
\hline b140 & Attention functions: & & \\
\hline b1400 & Sustaining attention & 2 & 1 \\
\hline b1401 & Shifting attention & 3 & 3 \\
\hline b144 & Memory functions: & & \\
\hline b1449 & Memory functions unspecified & 2 & 1 \\
\hline b152 & Emotional functions: & & \\
\hline b1522 & Range of emotion & 2 & 2 \\
\hline b156 & Perceptual functions: & & \\
\hline b1565 & Visuospatial perception & 2 & 3 \\
\hline b160 & Thought functions: & & \\
\hline b1600 & Pace of thought & 1 & 1 \\
\hline b1601 & Form of thought & 1 & 1 \\
\hline b164 & Higher-level cognitive functions: & & \\
\hline b1641 & Organization and planning & 2 & 2 \\
\hline b1642 & Cognitive flexibility & 3 & 2 \\
\hline b1644 & Insight & 1 & 1 \\
\hline b167 & Mental nctions of language: & & \\
\hline b16719 & Expression of language unspecified & 2 & 1 \\
\hline b176 & Mental functions of sequencing complex movements & 1 & 1 \\
\hline
\end{tabular}

communication skills resulted in better conversational skills and interpersonal interactions.

\subsection{Taking the environment into account: Contextual factors}

The Contextual factors section relates to all personal and environmental factors that may have an influence on the person's level of functioning. They are divided in Environmental and Personal factors.

a) Environmental factors are external features of the physical, social and attitudinal world, which can have an impact on the individual's performance in a given moment. An element of the external world, which has a positive influence in the individual's functioning, is called a facilitator. Barriers and hindrances are elements of the external world, which have a negative influence on any domain of functioning. By including and system- atically identifying external sources of influence on functioning, professionals working with patients with brain injuries will be able to introduce this additional assessment as a new, standardized factor that will increase our understanding.

b) Personal factors are the internal variables that influence functioning. They are the personal attributes of the person that may have an influence on the individual's performance in a given moment. The ICF does not include a list of elements in this category, but neuropsychologists and clinical psychologists, as part of the brain injury rehabilitation team, are well trained in assessing personality factors that might contribute to a final level of functioning. Additional personal factors include age, lifestyle, habits, and educational background among others. This component should also contribute to a better understanding of the nature of the interactions between 
cognition and everyday functioning in the ICF global model of functioning and disability.

Several assistive devices were helpful in increasing JM's independence such as a memory book, cell phone, adapted toilet and shower room to compensate for visual deficits. Other facilitators were supportive immediate and extended family, but not as well friends. His family supported him in finding resources and facilitating means for him to attend to those resources. At the same time attitudes of immediate family members who were non-supportive and demanding increased JM's stress level and limited the generalization of skills learnt at the rehabilitation center at home. Similarly his personal premorbid personality and beliefs described in Table 3 were other main barriers limiting JM's functioning and rehabilitation. Limitation of social support and educational services were main hindrances to further improvement and maintenance for JM. Main work at the contextual level focused on adapting his household and finding assistive devices and doing therapy with JM and his family to reduce irrational beliefs and enhance supportive behavior.

\section{Applications of the ICF in acquired brain injury rehabilitation}

Professionals working in the field of brain injury rehabilitation are skilled in measuring and describing physical and cognitive capacities. However, environmental, and personal factors can influence the expression of those capacities in real life everyday functioning. Through personality testing we might be able to describe some of the relevant personal factors, but there is a need for instruments that can describe in a standardized way the cultural and physical features of the environment that may have an external influence in behavior. The adoption by multidisciplinary teams of a conceptual framework incorporating these domains will enhance rehabilitation practice.

The ICF incorporates extensive subcategories for environmental factors and the range of functioning from small, individual, basic tasks or actions to broader societal-level functioning in life situations. In addition detailed subcategories for cognitive, emotional, and motor functions and related Central Nervous System (CNS) structures have been included in the classification. The ICF allows a standardized and comprehensive analysis of health and health related consequences, which is fully applicable to the field of neuroscience and specifically to Acquired Brain injury rehabilitation. Applications for this field extend to such as broad areas as clinical work (assessment, and rehabilitation therapies), research, and public health.

\subsection{Applications for clinical practice}

\subsubsection{Consulting}

Consulting in brain injury rehabilitation cases usually serves two purposes: medical care, and determination of the level of performance and determination of the level of capacity. When professionals in brain injury rehabilitation are asked to conduct an evaluation of cognitive and behavioral strengths and weaknesses for treatment planning, and the assessment of outcome, they are collaborating directly in the patient's medical care. To accomplish this professionals working with patients with brain injuries have developed a unified language that is highly efficient in communicating with other professionals.

Non-clinical consulting requires a different communication system. Insurance companies and legal systems are in need of a unified classification and codification system of physical, cognitive, emotional, and social impairments and disabilities caused by CNS dysfunction. Including a standardized system for the classification of disabilities, in both individual and societal terms, which takes into account the patient's specific environment, is the most innovative contribution of this version of the ICF. Communication with these types of clients (insurance companies and legal services) should be highly efficient. The ICF accurately provides a description of deficits, limitations and restrictions, at body, activity, and participation levels in a standardized codification system, which allows more efficient exchange of information.

In addition to its applications in the legal and compensatory systems, the ICF has three important applications for consulting with patients with brain injuries. First, the development of the performance construct will allow the standardized assessment of true everyday functioning (performance). By studying the capacityperformance dichotomy brain injury professional will be able to better predict physical, emotional, and cognitive functioning as it will occur in real life. Second, the classification of social behavior will allow for standardized observations and thus the identification of correlates of social pitfall providing a more successful prediction and intervention for social difficulties associated with acquired brain injury. Third, the incorporation of the contextual factors category will allow the 
Table 4

Example of the ICF activities and participation component to describe main changes in JM's performance before and after the intervention

\begin{tabular}{|c|c|c|c|}
\hline \multirow[t]{2}{*}{ Code } & \multirow[t]{2}{*}{ Activity/Participation item name } & \multicolumn{2}{|c|}{ Qualifier } \\
\hline & & Before & After \\
\hline $\mathrm{d} 110$ & Watching & 2 & 1 \\
\hline d130 & Copying & 1 & 1 \\
\hline d1551 & Acquiring complex skills & 3 & 2 \\
\hline d160 & Focusing attention & 2 & 1 \\
\hline d166 & Reading & 3 & 1 \\
\hline d178 & Making decisions & 3 & 1 \\
\hline $\mathrm{d} 299$ & General tasks and demands, unspecified & 2 & 2 \\
\hline $\mathrm{d} 350$ & Conversation & 2 & 1 \\
\hline $\mathrm{d} 3559$ & Discussion unspecified & 2 & 1 \\
\hline $\mathrm{d} 450$ & Walking & 3 & 1 \\
\hline d4602 & Moving around/outside the home and other buildings & 3 & 1 \\
\hline d489 & Moving around using transportation & 3 & 2 \\
\hline d510 & Washing oneself & 3 & 0 \\
\hline d570 & Looking after one's health & 2 & 2 \\
\hline d629 & Acquisition of necessities & 3 & 3 \\
\hline d6300 & Preparing simple meals & 3 & 0 \\
\hline d6409 & Doing housework unspecified & 3 & 0 \\
\hline d799 & Interpersonal interactions and relationships, unspecified & 3 & 2 \\
\hline d839 & Education other specified and unspecified & 3 & 2 \\
\hline d859 & Work and employment, other specified and unspecified & 3 & 2 \\
\hline
\end{tabular}

Table 5

Example of the ICF environmental factor component to describe changes in main facilitators and barriers affecting JM's performance in functioning before and after the intervention

\begin{tabular}{llrr}
\hline Code & Environmental factor item name & \multicolumn{2}{c}{ Qualifier } \\
\cline { 3 - 4 } & & Before & After \\
\hline & Environmental facilitators & & \\
e1150 & Assistive products and technologies for personal use in daily living & +0 & +1 \\
e310 & Immediate family & +1 & +3 \\
e315 & Extended family & +2 & +3 \\
e320 & Friends & +0 & +0 \\
e5550 & Associations and organizational systems & +0 & +2 \\
e5800 & Health services & +2 & +2 \\
& Environmental barriers & & \\
e410 & Individual attitudes of immediate family members & 2 & 1 \\
e5750 & General social support service & 2 & 2 \\
e5850 & Educational and training services & 1 & 1 \\
\hline
\end{tabular}

standardized assessment of personal and environmental factors and the incorporation of these variables in the body-cognition-behavior equation, which in turn will result in an improved predictive model of behavior, as it will be adjusted to each patient's specific circumstances. Consequently, brain injury professionals may find that applying the ICF system, along with standardized cognitive instruments, will provide a more complete clinical assessment and assist in treatment planning.

The ICF is an accurate and efficient codification and communication system for use with disorders of the $\mathrm{CNS}$, as well as a valuable guide to assessing relevant features of the patient's environment. Its implementa- tion in this field should result in better more efficient patient service.

\subsubsection{Rehabilitation}

Neuro-rehabilitation focuses on the reduction of the physical, cognitive, emotional and social deficits, limitations and restrictions caused by a neurologic condition. The field of rehabilitation is, perhaps, the one in which the ICF will have its greatest contribution, offering a unique theoretical and practical classification model. In the specific area of neuro-rehabilitation it applies directly to two main components; evaluation of deficits and identification of treatment goals and targets for intervention. The ICF provides a framework 
for the standardized assessment of the patient's current behavior and specific relevant environmental factors.

In the area of the identification of goals of intervention, the ICF offers a unique framework. The Capacity qualifier represents a traditional assessment of the optimal level of functioning of a patient in a uniform environment (neutral environment, free of barriers and/or assistance). For example, neuropsychologists usually assess the ability to memorize words or shift attention in a quiet, well-lighted office (or laboratory) setting that is free of distracting stimuli. Determining the rating of the capacity qualifier is a professional task and requires standardized assessment and clinical judgment based on experience. Brain injury rehabilitation professionals are experts in the utilization of well-validated tests and scales to ensure a high level of neutrality in the determination of an individual's physical, cognitive, emotional, or behavioral, capacity. The Performance qualifier in the Activities and Participation section represents the patient's actual level of functioning at both the individual and societal level. It can be used as a baseline to establish goals and measure functional changes in rehabilitation. The assessment of performance is ideally done through ecological observation, but may be done in simulated settings, or by self-report. Physical and occupational therapist are experts in evaluating a patient's performance in real life and simulated environments. Similarly, neuropsychologists and physicians are now standardizing their behavioral observations and reports of family members developing scales that focus on true functioning to complement their evaluation on cognitive and physical abilities.

When studying the relationship between capacity and performance in neurorehabilitation, the professional will need to explain some of the capacityperformance variance through the environmental factors. By taking into account all possible, body structures (CNS impairment) and functions and all environmental factors that may influence a patient's performance level one can determine which elements of his body, or personal environment should be modified on to enhance rehabilitation. At the environmental level one will be able to identify barriers and hindrances, as well as facilitators (i.e. assistive devices, technology, personal assistance), that can have a specific influence on that individual's current functioning. For example, lack of drive might compromise one patient's rehabilitation, whereas another patient might need more family support. Physical barriers might be responsible for one patient's resistance to attending school, whereas school peers' attitude might represent an important barrier to another patient's school re-entry. In other cases one may identify no environmental barriers but will discover that cognitive difficulties have developed as CNS maturation has taken place, compromising a patient's integration in school. The identification of targets for intervention will come from the detailed analysis of environmental factors. The ICF provides a model for identification of influences on health states and potential intervention strategies.

\subsection{Applications for research}

Research is another area in which professionals working in the area of neurorehabilitation will find very interesting applications for the ICF. The classification provides many possibilities (prompts), which encourages the consideration of a wide range of variables and consequences of disease. Instead of merely assessing the patient's physical and cognitive functioning the ICF facilitates an understanding of the environment in which the subject performs his everyday tasks and activities and provides an assessment of the weight that each variable (i.e. physical impairment, environment, personality factors, intervention) has on real life functioning. The ICF allows that kind of evaluation through the inclusion of measures of everyday functioning (Activities and Participation-Performance qualifier) and the environmental factors. A more precise understanding of the nature of the effects of treatment and the recovery process by taking into account a wider range of variables will assist in a better understanding of the mechanisms of healing and rehabilitating, and aid in the design of more effective treatments and interventions

Similarly, the ICF opens the possibility of detailed classification of the effects of neurologic disease in physical, emotional, and cognitive capacities and performance at the individual and societal levels. By using the Activities and Participation codes and the performance qualifier we will get closer to assessing the person's actual level of functioning in individual and social activities in a consistent manner. The ICF will allow predictive models of general or specific areas of functioning. For example, the development of measures of the participation component will allow a more comprehensive study of the effects of acquired brain injury on societal dysfunction.

The ICF will enhance the development of instruments, which evaluate the relationship between psychomotor and cognitive domains and specific life tasks and activities (interactions between capacities and per- 
formance at the activity and participation levels). It will also facilitate the study of the continuity of these interactions within and across disease populations, cultures and age groups. This has important implications for the development of assessment tools for patients with brain injuries. The performance qualifier has the potential to become a measure that can be used in the validation process of different instruments. The classification system is also important for understanding determinants of impairments; how biological and environmental factors interact in a specific personal situation to result in a particular level of functioning. Improved understanding of these interactions will likely facilitate the development of improved intervention strategies tailored to the individual case.

One of the applications of the ICF is in keeping track of specific health states in general populations. It is a new tool for epidemiologists and researchers who are interested in the physical, cognitive, and emotional impairments, limitations in individual functioning (activities) and restrictions in social involvement (participation) that occur in brain injury. The data collected by the WHO for individual countries will provide a more accurate reflection of population needs, allowing a better understanding of our regional, national, and international differences and needs in the area of neurorehabilitation. This understanding will allow the development of more efficient public health management and will have a direct impact on public policies, compensation systems. Most important, through a good understanding of all variables that intervene in neurodisability we will be able to plan medical, social, educational, and compensatory resources for better care of future brain injury survivors. By implementing this classification system there may be an increased institutional awareness of this at risk populations. This may in turn have a positive impact on the situation of brain injury rehabilitation survivors in many countries through the development of new intervention and research programs, units and institutions and the inclusion of specific therapeutic techniques and financial compensations in public and private health insurance policies.

The implementation of the classification model will permit the comparison of data across countries, health care disciplines, services and time. This should result in the development of more efficient public health policies based on cross-cultural scientific research, which takes into account many important physical, psychological, social and environmental variables.

Finally, we must point out that the efforts and interest of the WHO in the area of disability, reflected in the development of the ICF, represents, for many countries, a step towards public sensitization to the needs of people with neurodisabilities, and the development of neurodisability sensitive legislation.

\section{Conclusions and future developments}

The ICF is an interactive model of functioning and disability. It has been developed as a cross-cultural classification system to facilitate communication and efficient evaluation in the area of disability. The ICF has important applications in the fields of brain injury consulting, rehabilitation, research and public health. The inclusion in the model of standardized Environmental factors, the multidimensional view of disability that includes body functions and structures, activities and participation, and the constructs of Capacity and Performance are the most important contributions of the ICF, to the applicability of the model in the field of acquired brain injury rehabilitation. They allow the study of the interactions between abilities and real life functioning at both the individual and societal levels. They are the most innovative elements of the global model developed in the ICF. In addition, the interactive model allows a number of analyses using a multitude of variables for more effective predictive models. The ICF can also be used as a public health or statistical model that will allow the study of health related impairments at the physical, individual, and societal levels, facilitating documentation and policy formulation in the area of neuro-disability.

Future work of the ICF in brain injury rehabilitation should focus on:

1) Dissemination of the classification and training of professionals in its use.

2) Development of instruments that will allow the measurement of the main constructs of the model. Well-established and standardized measurement instruments exist for physical and cognitive functioning and CNS dysfunction structures brain injury rehabilitation professionals are used to work with a variety of well-validated instruments for specific areas and uses. However, physiological, psychological, cognitive and sensory-motor functioning influence and are influenced by other areas of the model that do not have such accurate and specific evaluation instruments. The WHO is planning a new program to develop, where needed, new instruments to allow the application 
of the ICF in obtaining information that will complement traditional measures of physical cognitive, and emotional functioning to allow multiple uses.

3) Once professionals are trained and new instruments developed, worldwide epidemiological studies will be conducted by the WHO and other organizations in order to detect future needs in the different areas, including neurorehabilitation.

The ICF has made great strides both in classifying the effects of health conditions and in applying the concept, documentation, and quantification of these effects to both a broader group of users as well as adding more depth to its applicability within the field of health. The great strides accomplished by the ICF revision process were possible through advances in medical knowledge, social awareness, and use of the ICIDH in clinical situations, in research, and in surveys. Through such applications, like the ones suggested here in neurorehabilitation, will future refinements be brought to light. This evolution serves to bring progress to the field of brain injury rehabilitation as well.

\section{References}

[1] American Psychiatric Association, Diagnostic and Statistical Manual of Mental Disorders, Fourth Edition, American Psychiatric Association, Washington, DC, 1994.

[2] M. Chamie, The status and use of the international classification of impairments, disabilities and handicaps (ICIDH), World Health Statistics 43 (1990), 273-280.

[3] J. Dekker, Applications of the ICIDH in survey research on rehabilitation: the emergence of functional diagnosis, Disability and Rehabilitation 17(3/4) (1995), 195-201.

[4] M. de Kleijn de Vrankrijker, C. Seidel and U. Tscherner, The International Classification of Impairments, Disabilities and Handicaps (ICIDH): Its use in rehabilitation, World Health Statistics 42 (1989), 151-155.

[5] World Health Organization, International Classification of Functioning, Disability and Health, World Health Organization, Geneva, 2001. http://www3.who.int/icf/icftemplate.cfm.

[6] World Health Organization, International Statistical Classification of Diseases and Related Health Problems, Tenth Revision, World Health Organization, Geneva, 1992.

[7] World Health Organization, Application of the International Classification of Diseases to Neurology (ICD-9 NA), World Health Organization, Geneva, 1987.

[8] World Health Organization, International Classification of Impairments, Disabilities and Handicaps: A manual of classification relating to consequences of disease, World Health Organization, Geneva, 1980.

[9] World Health Organization, The constitution of the World Health Organization, World Health Organization, (1947), Chronicle 1, 29. 